\title{
Case-mix \& patients' reports of outcome in Independent Sector Treatment Centres: Comparison with NHS providers John Browne ${ }^{1,2}$, Liz Jamieson², Jim Lewsey ${ }^{1,2}$, Jan van der Meulen ${ }^{1,2}$, Lynn Copley² and Nick Black*1
}

\author{
Address: ${ }^{1}$ Health Services Research Unit, London School of Hygiene \& Tropical Medicine, UK and ${ }^{2}$ Clinical Effectiveness Unit, Royal College of \\ Surgeons, UK \\ Email: John Browne - john.browne@lshtm.ac.uk; Liz Jamieson - ljamieson@rcseng.ac.uk; Jim Lewsey - jdl6d@clinmed.gla.ac.uk; Jan van der \\ Meulen - jan.vanderMeulen@lshtm.ac.uk; Lynn Copley - lcopley@rcseng.ac.uk; Nick Black* - nick.black@lshtm.ac.uk \\ * Corresponding author
}

Published: 9 April 2008

BMC Health Services Research 2008, 8:78 doi:10.1186/1472-6963-8-78

This article is available from: http://www.biomedcentral.com/I472-6963/8/78

(C) 2008 Browne et al; licensee BioMed Central Ltd.

This is an Open Access article distributed under the terms of the Creative Commons Attribution License (http://creativecommons.org/licenses/by/2.0), which permits unrestricted use, distribution, and reproduction in any medium, provided the original work is properly cited.

\begin{abstract}
Background: There has been considerable concern expressed about the outcomes achieved in Independent Sector Treatment Centres (ISTCs) introduced in England since 2003. Our aim was to compare the case-mix and patients' reported outcomes of surgery in ISTCs and in NHS providers.

Methods: Prospective cohort study of 769 patients treated in six ISTCs and 1895 treated in 20 NHS providers (acute hospitals and treatment centres) in England during 2006-07. Participants underwent one of three day surgery procedures (inguinal hernia repair, varicose vein surgery, cataract extraction) or hip or knee replacement. Change in patientreported health status and health related quality of life (measured using a disease-specific and a generic (EQ-5D) instrument) was assessed either 3-months (day surgery) or 6-months (hip/knee) after surgery. In addition patientreported post-operative complications and an overall assessment of success of surgery were collected. Outcome measures were adjusted (using multivariable regression) for patient characteristics (disease severity, duration of symptoms, age, sex, socioeconomic status, general health, previous similar surgery, comorbidity).
\end{abstract}

Results: Post-operative response rates varied by procedure (73\%-88\%) and were similar for those treated in ISTCs and NHS facilities. Patients treated in ISTCs were healthier, were less likely to have any comorbidity and, for those undergoing cataract surgery or joint replacement, their primary condition was less severe. Those undergoing hernia repair or joint replacement were less likely to have had similar surgery before.

When adjustment was made for pre-operative characteristics, patients undergoing cataract surgery or hip replacement in ISTCs achieved a slightly greater improvement in functional status and quality of life than those treated in NHS facilities, while the opposite was true of patients undergoing hernia repair. No significant differences were found for the two other procedures. Patients treated in ISTCs were less likely to report post-operative problems than those treated in NHS facilities for cataract surgery (Adjusted Odds Ratio 0.35 ; $95 \% \mathrm{Cl} 0.17-0.70$ ), hernia repair $(0.42 ; 0.28-0.63$ ) and knee replacement $(0.44 ; 0.28-0.69)$. Most patients described the result of their operation as excellent, very good or good, regardless of where they were treated.

Conclusion: The case-mix of patients treated in ISTCs differs from that in NHS providers, in line with the intention of the contracts. Caution is needed in interpreting the observation that patients treated in ISTCs reported slightly better outcomes as very few ISTCs participated, case-mix adjustment might have been insufficient, and patients' reports might have been biased as they were more likely to be satisfied with the way they were treated. 


\section{Background}

In 2002 the Department of Health committed to increasing the permanent capacity for elective surgery (and diagnostic services) in England by establishing more Diagnosis and Treatment Centres [1]. The aim was not only to reduce waiting times for routine procedures but also to expand choice and to increase productivity through innovative models of care. Unlike the ten existing NHS centres (including one run jointly with a private provider), expansion was partly to be achieved by encouraging private companies to establish facilities employing staff not currently working for the NHS, thus creating additional capacity in England. The first of these Independent Sector Treatment Centres (ISTCs), focusing on low risk ophthalmic, orthopaedic and day surgery, opened in 2003. By October 2004, six centres had been established and had treated 16000 patients [2].

Following some concerns about the policy of introducing ISTCs $[3,4]$, the House of Commons Health Committee undertook a review in spring 2006. In addition to receiving evidence about poor value for money, adverse impact on surgical training, loss of continuity of care, lack of adequate clinical governance, and jeopardising the viability of existing NHS providers, clinicians reported seeing serious complications in patients who had been treated in ISTCs [5-8]. However, as some of them acknowledged, meaningful comparisons with NHS providers could not be made both because of the poor quality of the data collected by ISTCs [9] and the historical lack of routine data on outcome collected by the NHS. When the Health Committee reported in July 2006, it agreed "that there was no hard, quantifiable evidence to prove that standards in ISTCs differed from those in the NHS" and "recommended that comparable and standardised data be collected" [10]. This was welcomed by clinicians [11], some of whom had been advocating such an approach [12].

Meanwhile, in April 2006 the Secretary of State for Health pre-empted the Health Committee's report by announcing the establishment of "a wide-ranging clinical audit" to be carried out by the Healthcare Commission [13]. However, inevitably, when it appeared in July 2007, it too confirmed the lack of available routine data with which to assess outcomes [14].

Fortunately, in 2004 the Department of Health's Economic and Operational Research Division foresaw the need for meaningful comparisons of the performance of providers in the emerging world of choice. They commissioned a project to review international evidence on patient-reported outcome measures for five elective surgical procedures and to establish a demonstration project with three objectives: to test the feasibility of data collection in ISTCs and NHS providers; to establish how best to analyse the data; and to explore how best to present interprovider comparisons. As only two ISTCs agreed to take part, the DH Commercial Directorate subsequently funded data collection from an additional four centres. These combined data provide the first opportunity to address some of the concerns of clinicians, the Health Committee, independent sector providers and policymakers.

In this paper our objectives are to compare the case-mix of ISTCs and NHS providers (acute hospitals and treatment centres) and patient-reported outcomes in terms of change in health status/quality of life, post-operative complications and overall result of surgery. Comparisons of individual centres will appear elsewhere.

\section{Methods}

Twenty-six providers (13 NHS hospitals, 7 NHS treatment centres, 6 ISTCs) participated. Ethical approval was granted by the Wales MREC. Consecutive patients (apart from those with cognitive impairment, poor sight, literacy or language comprehension problems) were eligible. Recruitment, which lasted for up to six months between January 2006 and April 2007, was carried out by nursing or administrative staff who explained what the study involved (completion of a pre and post-operative questionnaire) and obtained written consent. This took place either in a pre-operative assessment clinic or on admission for surgery. The pre-operative questionnaire that included: age, sex and postcode (to determine an Index of Multiple Deprivation [15] - higher scores indicate more deprived); duration of symptoms; history of previous similar surgery; general health status (five categories); comorbidities [16]; and the EQ-5D, a generic measure of health-related quality of life [17]. In addition, a diseasespecific measure of functional status/health-related quality of life was included: the VF14 for cataract surgery [18]; the Aberdeen Varicose Vein Questionnaire - AVVQ [19]; the Oxford Hip Score - OHS [20]; and the Oxford Knee Score - OKS [21]. As no specific measure for hernia repair has been validated, the Physical Component Summary (PCS) of the SF-36 was used [22]. Higher scores represent better outcomes for the EQ-5D, the PCS and the VF14. The reverse is true for the OHS, OKS and the AVVQ.

Post-operative questionnaires were mailed three (for hernia, cataract and varicose vein surgery) or six months (joint replacement) after surgery to patients' homes from the Royal College of Surgeons of England. Non-responders were sent a reminder letter and replacement questionnaire five weeks after the original mailing. The questionnaires contained: general health status; EQ-5D; a relevant disease-specific instrument; a question relating to complications - "Did you experience any of the following problems after your operation?" (allergy or reaction to 
drug, and urinary, bleeding or wound problems) [23]; and a global evaluation - "How would you describe the results of your operation?".

Summary statistics of pre-operative characteristics are reported for each operation group by treatment sector. Post-operative response bias was investigated by using ttests to compare the pre-operative disease-specific instrument scores of patients who did and did not respond. The primary outcomes were the post-operative generic and disease-specific PROM scores, adjusted for pre-operative patient characteristics (age, sex, socioeconomic status, comorbidities, duration of symptoms, previous similar surgery, general health status, EQ-5D). Secondary outcomes were the risk-adjusted proportions of patients reporting any complications and rating their operation as excellent, very good, or good.

Risk-adjustment of outcomes was conducted using linear regression (logistic regression for post-operative complication incidence and overall operation success) with preoperative PROM scores and other patient characteristics (age, sex, general health status, duration of symptoms, number of comorbidities, Index of Multiple Deprivation, previous similar surgery) being potential risk factors.

To account for possible clustering of patient outcomes within hospitals, we used robust standard errors. All P values are 2-sided and P values lower than 0.05 were considered a statistically significant result. Stata software was used for all calculations [24].

\section{Results}

\section{Recruitment and response rates}

During the recruitment period, 769 patients were recruited in ISTCs and 1895 in NHS providers. Data on the number of eligible patients were not obtained in 2 ISTCs and 3 NHS centres. However, in the other 4 ISTCs and 17 NHS centres, the proportion of eligible patients recruited in the ISTCs was higher: cataract surgery $72 \% \mathrm{v}$ $66 \%$; hernia repair $62 \%$ v $50 \%$; varicose vein surgery $84 \%$ v 66\%; hip replacement 98\% v 54\%; and knee replacement $100 \%$ v $56 \%$.

There was little difference in post-operative response rate between patients treated in ISTCs and NHS facilities: cataract surgery $84 \%$ v $86 \%$; hernia repair $70 \%$ v $77 \%$; varicose vein surgery $68 \% \mathrm{v} 74 \%$; hip replacement $77 \% \mathrm{v}$ $88 \%$; and knee replacement $85 \% \mathrm{v} 88 \%$. In both treatment sectors and across all five procedures a comparison of the pre-operative disease-specific PROM scores of those who did and did not return a post-operative questionnaire revealed no statistically significant differences.

\section{Case-mix}

Generally, patients undergoing day surgery in ISTCs were healthier and had a less severe primary condition than those in NHS facilities (Table 1): cataract patients were less likely to be in poor/fair health or to suffer any comorbidity, and their visual function was better; hernia patients were younger, had less comorbidity, had a shorter duration of symptoms, and were less likely to have undergone hernia repair before; and varicose vein patients were younger and were less likely to be in poor/fair health.

Similar differences were observed for those undergoing joint replacement (Table 2): patients treated in ISTCs were less likely to be in poor/fair health or to suffer any comorbidity, their primary condition was less severe and, for hips, they were less likely to have undergone previous similar surgery.

Table I: Pre-operative characteristics of day surgery patients

\begin{tabular}{|c|c|c|c|c|c|c|}
\hline \multirow[t]{3}{*}{ Patient characteristic } & \multicolumn{2}{|c|}{ Cataract surgery } & \multicolumn{2}{|c|}{ Hernia repair } & \multicolumn{2}{|c|}{ Varicose vein surgery } \\
\hline & NHS $(N=590)$ & ISTC $(N=276)$ & $\mathrm{NHS}(\mathrm{N}=422)$ & ISTC (N = 69) & $\mathrm{NHS}(\mathrm{N}=269)$ & $\operatorname{ISTC}(\mathrm{N}=53)$ \\
\hline & Mean (SD) & Mean (SD) & Mean (SD) & Mean (SD) & Mean (SD) & Mean (SD) \\
\hline Age (years) & $73.7(10.6)$ & $74.6(10.0)$ & $53.4(18.0)$ & $48.7(14.1)$ & $46.6(13.5)$ & $42.2(16.5)$ \\
\hline Duration symptoms (years) & $2.8(3.7)$ & $2.6(3.0)$ & $2.8(5.6)$ & $1.6(1.9)$ & $13.6(11.5)$ & $12.8(8.6)$ \\
\hline Deprivation score & $20.3(14.1)$ & $16.5(9.3)$ & $18.6(15.5)$ & $33.2(18.9)$ & $20.1(14.8)$ & $33.4(21.7)$ \\
\hline EQ-5D score & $0.80(0.24)$ & $0.84(0.22)$ & $0.78(0.18)$ & $0.76(0.19)$ & $0.76(0.19)$ & $0.78(0.16)$ \\
\hline \multirow[t]{2}{*}{ Disease-specific score } & $81.8(17.9)$ & 84.7 (I5.9) & $47.2(9.2)$ & $46.6(9.2)$ & $16.9(8.3)$ & $15.8(8.4)$ \\
\hline & $\mathrm{N}(\%)$ & $\mathrm{N}(\%)$ & $\mathrm{N}(\%)$ & $\mathrm{N}(\%)$ & $\mathrm{N}(\%)$ & $\mathrm{N}(\%)$ \\
\hline Female & $340(57.7)$ & $156(56.5)$ & $47(I 1.1)$ & $3(4.3)$ & $178(66.2)$ & $33(62.3)$ \\
\hline Any comorbidity & $465(78.8)$ & 197 (7I.4) & $207(49.1)$ & $27(39.1)$ & $160(59.5)$ & $25(57.2)$ \\
\hline Previous similar surgery & $202(34.5)$ & $90(32.7)$ & $84(20.2)$ & $9(13.4)$ & $86(32.7)$ & 15 (28.9) \\
\hline Poor or fair health & $131(22.3)$ & $45(16.4)$ & $34(8.1)$ & $4(5.8)$ & $27(10.2)$ & $3(5.7)$ \\
\hline
\end{tabular}


Table 2: Pre-operative characteristics of joint replacement patients

\begin{tabular}{|c|c|c|c|c|}
\hline \multirow[t]{3}{*}{ Patient characteristic } & \multicolumn{2}{|c|}{ Hip replacement } & \multicolumn{2}{|c|}{ Knee replacement } \\
\hline & NHS (N = 29I) & $\operatorname{ISTC}(N=184)$ & NHS (N = 323) & $\operatorname{ISTC}(\mathrm{N}=187)$ \\
\hline & Mean (SD) & Mean (SD) & Mean (SD) & Mean (SD) \\
\hline Age (years) & $66.2(14.6)$ & $66.8(14.1)$ & $66.2(16.5)$ & $66.7(12.2)$ \\
\hline Duration symptoms (years) & $3.9(5.4)$ & $3.7(3.9)$ & $8.1(10.1)$ & $8.6(9.3)$ \\
\hline Deprivation score & $22.4(16.8)$ & $20.3(13.3)$ & $25.2(17.4)$ & $19.0(12.6)$ \\
\hline EQ-5D score & $0.31(0.3 I)$ & $0.35(0.32)$ & $0.36(0.32)$ & $0.45(0.30)$ \\
\hline \multirow[t]{2}{*}{ Disease-specific score } & $44.0(7.7)$ & $42.1(8.4)$ & $42.3(7.5)$ & $39.8(8.0)$ \\
\hline & $\mathrm{N}(\%)$ & $N(\%)$ & $N(\%)$ & $N(\%)$ \\
\hline Female & $157(54.1)$ & $108(58.7)$ & $167(52.0)$ & $96(51.6)$ \\
\hline Any comorbidity & $25 \mathrm{I}(86.2)$ & $148(80.4)$ & $280(86.7)$ & $15 \mid(80.7)$ \\
\hline Previous similar surgery & $79(27.3)$ & $34(18.6)$ & $168(53.3)$ & $78(42.6)$ \\
\hline Poor or fair health & $62(21.5)$ & $27(14.9)$ & $68(21.7)$ & $21(11.5)$ \\
\hline
\end{tabular}

\section{Patient-reported outcomes}

For all procedures, except hernia repair, post-operative PROM scores in ISTC patients indicated better outcomes than those treated by NHS providers (Table 3 ). However, when adjustment was made for pre-operative characteristics statistically significant differences persisted for cataract surgery and hip replacement, both favouring patients treated at ISTCs: cataract surgery patients achieved a significantly better outcome on the VF14 (2.6 points on a 100 -point scale, $\mathrm{p}=0.005)$ and the EQ-5D (0.03 points on a 0 to 1 scale, $\mathrm{p}=0.01)$; hip replacement patients on the OHS (2.4 points on a 70-point scale, $\mathrm{p}=0.03$ ) and the EQ-5D (0.06 points, $\mathrm{p}=0.03)$.

Fewer patients treated in ISTCs reported a post-operative complication than patients treated in NHS facilities, even after adjusting for pre-operative risk factors (Table 4).
These differences were statistically significant for cataract surgery, hernia repair and knee replacement. Consideration of each of the four types of complication separately revealed that all four were reported less often by patients undergoing these procedures in ISTCs (Table 5).

Most patients described the result of their operation as a success (i.e. excellent, very good or good) both in ISTCs and NHS facilities: cataract surgery $97 \%$ v $91 \%$; hernia surgery $98 \%$ v $94 \%$; varicose vein surgery $71 \%$ v $86 \%$; hip replacement $98 \%$ v $92 \%$; and knee replacement $85 \%$ v $87 \%$. Following risk adjustment patients undergoing varicose vein surgery in an ISTC were less likely to describe their operation as a success (Adjusted Odds Ratio 0.38; 95\% CI 0.15-0.90; $\mathrm{p}=0.03$ ) while those undergoing hernia surgery were more likely to declare it a success (Adjusted Odds Ratio 3.2; 95\% CI 1.2-8.1; p = 0.02).

Table 3: Unadjusted and adjusted post-operative PROM scores by operation

\begin{tabular}{|c|c|c|c|c|c|}
\hline \multirow[t]{2}{*}{ PROMs } & \multicolumn{2}{|l|}{$\mathrm{NHS}$} & \multirow[t]{2}{*}{ Adjusted difference* } & \multirow[t]{2}{*}{$95 \% \mathrm{Cl}$} & \multirow[t]{2}{*}{ P-value } \\
\hline & Mean (SD) & Mean (SD) & & & \\
\hline \multicolumn{6}{|l|}{ EQ-5D } \\
\hline Cataract & $0.77(0.28)$ & $0.84(0.23)$ & 0.03 & 0.009 to 0.06 & 0.01 \\
\hline Hernia & $0.85(0.21)$ & $0.84(0.22)$ & -0.02 & -0.05 to 0.002 & 0.07 \\
\hline Varicose vein & $0.87(0.20)$ & $0.89(0.19)$ & 0.005 & -0.03 to 0.04 & 0.8 \\
\hline Hip & $0.72(0.26)$ & $0.82(0.20)$ & 0.06 & 0.005 to 0.11 & 0.03 \\
\hline Knee & $0.70(0.26)$ & $0.76(0.22)$ & 0.03 & -0.02 to 0.08 & 0.2 \\
\hline \multicolumn{6}{|l|}{ Disease-specific } \\
\hline Cataract (VFI4) & $92.3(15.2)$ & $96.2(7.8)$ & 2.6 & 0.97 to 4.2 & 0.005 \\
\hline Hernia (PCS) & $50.1(9.6)$ & $51.8(10.5)$ & 1.2 & -0.52 to 2.9 & 0.2 \\
\hline Varicose vein (AVVQ) & $10.3(9.0)$ & $8.6(7.9)$ & 1.3 & -3.1 to 0.49 & 0.5 \\
\hline $\mathrm{Hip}(\mathrm{OHS})$ & $23.9(9.9)$ & $20.5(7.6)$ & 2.4 & -4.4 to -0.36 & 0.03 \\
\hline Knee (OKS) & $27.0(9.3)$ & $24.2(8.8)$ & 0.86 & -3.7 to 2.0 & 0.5 \\
\hline
\end{tabular}

*positive adjusted differences indicate better post-operative scores for ISTC patients 
Table 4: Proportion of patients reporting at least one complication by operation

\begin{tabular}{|c|c|c|c|c|c|}
\hline \multirow[t]{2}{*}{ Surgery type } & NHS & ISTC & \multirow[t]{2}{*}{ Adjusted odds ratio } & \multirow[t]{2}{*}{$95 \% \mathrm{Cl}$} & \multirow[t]{2}{*}{ P-value } \\
\hline & $\mathrm{N}(\%)$ & $\mathrm{N}(\%)$ & & & \\
\hline Cataract surgery & $58(I \mid .5)$ & $9(3.9)$ & 0.32 & 0.14 to 0.70 & 0.004 \\
\hline Hernia repair & $79(24.4)$ & $8(16.7)$ & 0.46 & 0.32 to 0.66 & $<0.001$ \\
\hline Varicose vein & $83(4 \mid .5)$ & $13(36.1)$ & 0.75 & 0.42 to 1.3 & 0.3 \\
\hline Hip replacement & 87 (33.9) & $4 I(29.1)$ & 0.87 & 0.52 to 1.5 & 0.6 \\
\hline Knee replacement & $112(39.6)$ & $39(24.5)$ & 0.43 & 0.27 to 0.69 & $<0.001$ \\
\hline
\end{tabular}

\section{Discussion}

\section{Findings}

In line with their contracts, ISTCs tend to treat healthier patients with less severe primary conditions. Having adjusted for such differences in case-mix, patients reported similar improvements in function and healthrelated quality of life following hernia repair, varicose vein surgery and knee replacement in ISTCs and NHS providers. Improvements following cataract surgery and hip replacement were slightly greater in patients treated in ISTCs. There was also a lower incidence of complications reported by ISTC patients undergoing cataract, hernia and knee surgery.

\section{Limitations}

There are four reasons for caution in interpreting these comparisons between ISTCs and NHS providers. First, although a high proportion of eligible patients were recruited in the ISTCs, the small number of ISTCs that participated limits the generalisability of the results. While patients undergoing joint replacement were recruited from four ISTCs, only one ISTC was involved for hernia and varicose vein surgery. Second, a lower proportion of patients were recruited in NHS centres than in ISTCs. It is possible that this difference could have introduced a bias. Third, the risk adjustment models had only poor predictive power (area under ROC curve about 0.6). It is probable that the addition of clinician-reported data would

Table 5: Proportion of patients reporting complications by operation

\begin{tabular}{|c|c|c|c|c|c|}
\hline \multirow[t]{2}{*}{ Operation } & \multirow{2}{*}{$\begin{array}{c}\text { NHS } \\
\mathrm{N}(\%)\end{array}$} & \multirow{2}{*}{$\begin{array}{l}\text { ISTC } \\
\mathrm{N}(\%)\end{array}$} & \multirow[t]{2}{*}{ Adjusted odds ratio } & \multirow[t]{2}{*}{$95 \% \mathrm{Cl}$} & \multirow[t]{2}{*}{$P$-value } \\
\hline & & & & & \\
\hline \multicolumn{6}{|l|}{ Cataract } \\
\hline Bleeding & $17(3.4)$ & $5(2.2)$ & 0.74 & 0.37 to 1.5 & 0.4 \\
\hline Wound infection & $18(3.6)$ & $2(0.9)$ & 0.13 & 0.02 to 1.0 & 0.05 \\
\hline Urinary problems & $12(2.4)$ & $\mathrm{I}(0.4)$ & 0.26 & 0.03 to 2.5 & 0.2 \\
\hline Adverse drug reaction & $19(3.8)$ & $4(1.7)$ & 0.53 & 0.19 to 1.5 & 0.2 \\
\hline \multicolumn{6}{|l|}{ Hernia repair } \\
\hline Bleeding & $19(5.9)$ & $2(4.2)$ & 0.80 & 0.35 to 1.8 & 0.6 \\
\hline Wound infection & $35(10.8)$ & $4(8.3)$ & 0.58 & 0.33 to 1.0 & 0.06 \\
\hline Urinary problems & $20(6.2)$ & $3(6.2)$ & 0.82 & 0.43 to 1.5 & 0.5 \\
\hline Adverse drug reaction & $21(6.5)$ & $\mathrm{I}(2.1)$ & 0.16 & 0.10 to 0.27 & $<0.001$ \\
\hline \multicolumn{6}{|l|}{ Varicose vein surgery } \\
\hline Bleeding & 51 (25.5) & $8(22.2)$ & 0.71 & 0.30 to 1.7 & 0.4 \\
\hline Wound infection & $50(25.0)$ & $9(25.0)$ & 1.2 & 0.74 to 2.0 & 0.4 \\
\hline Urinary problems & $7(3.5)$ & I (2.8) & 1.2 & 0.46 to 3.3 & 0.7 \\
\hline Adverse drug reaction & $10(5.0)$ & $0(0)$ & 1.0 & 0.94 to 1.0 & 0.7 \\
\hline \multicolumn{6}{|l|}{ Hip replacment } \\
\hline Bleeding & $27(10.5)$ & $10(7.1)$ & 0.88 & 0.47 to 1.7 & 0.7 \\
\hline Wound infection & $27(10.5)$ & $15(10.6)$ & 1.2 & 0.58 to 2.6 & 0.6 \\
\hline Urinary problems & $33(12.8)$ & $12(8.5)$ & 0.67 & 0.35 to 1.3 & 0.2 \\
\hline Adverse drug reaction & $29(11.3)$ & $15(10.6)$ & 0.84 & 0.39 to 1.8 & 0.6 \\
\hline \multicolumn{6}{|l|}{ Knee replacement } \\
\hline Bleeding & $25(8.8)$ & $7(4.4)$ & 0.45 & 0.14 to 1.4 & 0.2 \\
\hline Wound infection & $42(14.8)$ & $14(8.8)$ & 0.50 & 0.28 to 0.90 & 0.02 \\
\hline Urinary problems & $42(14.8)$ & $13(8.2)$ & 0.51 & 0.29 to 0.88 & 0.02 \\
\hline Adverse drug reaction & $39(13.8)$ & $16(10.1)$ & 0.65 & 0.43 to 0.97 & 0.04 \\
\hline
\end{tabular}


improve the predictive power of our models. Fourth, there may have been some reporting bias. If ISTC patients were more satisfied with their experience, as has been reported $[14]$, they may have been less critical of their outcome.

While not undermining comparisons between types of provider, the validity and reliability of the absolute values reported could be challenged. Although the instruments used were the best available in psychometric terms, the validity of at least one (the VF14) has been challenged by clinicians [25], though it is unclear how justified such criticism is. Another concern is the validity of patients' reporting of complications: patients may wrongly attribute a problem to the operation and/or they may interpret normal post-operative recovery, such as some wound discomfort, to be a 'complication'. Despite these concerns, there is evidence that the question has sufficient construct validity for comparative purposes: reports of bleeding and wound problems were much higher following varicose vein surgery (around 25\%) than after cataract surgery (around 3\%) and the incidence of urinary problems was higher after joint replacement $(12 \%)$ than after hernia repair $(6 \%)$ or varicose vein or cataract surgery $(2-3 \%)$.

\section{Implications}

These, the first quantitative data to cast light on the effectiveness of surgery in ISTCs, suggest there is no widespread problem with poor quality care. Indeed, the lower incidence of patient-reported complications following treatment in an ISTC is reassuring. These findings do not refute previous reports of individual instances of serious lapses in the quality care in some ISTCs, they simply suggest that such failures are uncommon. Inevitably, there is no information yet available as to the long-term outcomes.

Although these findings provide some systematic evidence about the effectiveness and safety of ISTCs, the conclusions have to be tentative given the relatively small sample of providers and patients. A larger sample would enable the generalisability of these findings to be tested, provide greater statistical power, and allow more robust risk-adjustment models to take into account case-mix differences. In addition, the inclusion of clinician-reported outcomes would allow an assessment of the effect of surgery on impairments (such as visual acuity and extent of joint movement) and enable a clinical view of the incidence of complications to be obtained. An audit of hip and knee replacements in all ISTCs and representative sample of NHS providers is due to start soon.

\section{Conclusion}

The case-mix of patients treated in ISTCs differs from that in NHS providers, in line with the intention of the contracts. Caution is needed in interpreting the observation that patients treated in ISTCs reported slightly better out- comes as very few ISTCs participated, case-mix adjustment might have been insufficient, and patients' reports might have been biased as they were more likely to be satisfied with the way they were treated.

\section{Competing interests}

The author(s) declare that they have no competing interests.

\section{Authors' contributions}

$\mathrm{JB}, \mathrm{NB}$ and JvdM conceived and designed the study; LJ and LC managed the data collection; JL analysed the data; NB drafted the paper and all authors contributed to the final draft. NB acts as guarantor.

\section{Acknowledgements}

We thank: the many patients who participated by completing questionnaires; the staff of the surgical centres who recruited patients and assisted in supplying data on the activity of their centres; John Sparrow, Paul Gregg, Andrew Kingsnorth, and Paul Edwards for clinical advice; John Cairns and Donna Lamping for methodological advice; and the Department of Health Policy Research Programme and the Commercial Directorate for funding the project on which these analyses are based.

\section{References}

I. NHS Executive: Growing Capacity: independent sector diagnosis and treatment centres. London: Department of Health; 2002.

2. NHS Executive: Treatment Centres: delivering faster, quality care and choice for NHS patients. London: Department of Health; 2005.

3. Pounder RE: Independent Sector Treatment Centres. Royal College of Physicians 2003 [http://www.rcplondon.ac.uk/news/state ments/doc IndepSector.asp].

4. Central Consultants and Specialists Committee: ISTCs - structured secondment and retention of employment. British Medical Association 2005 [http://www.bma.org.uk/ap.nsf/Content/ ISTCAug05guidance].

5. Royal College of Surgeons of England: RCS evidence to Health Committee Inquiry into ISTCs. [http://www.rcseng.ac.uk/ media/medianews/independentsectortreatmentcentres]. I6 February 2006.

6. Royal College of Ophthalmologists: Response to Health Select Committee. [http://www.rcophth.ac.uk/docs/college/CollegeRe sponsetoSelectCommlnquiryonISTCs.pdf].

7. Wallace WA: ISTCs: how the NHS is left to pick up the pieces. BMJ 2006, 332:6I4.

8. O'Dowd A: Surgeons claim independent centres produce poor results. $B M J$ 2006, 332:623.

9. National Centre for Health Outcomes Development: An overview of performance under the ISTC programme. London: NCHOD; 2005.

10. House of Commons Health Committee: Independent Sector Treatment Centres. In Fourth Report of Session 2005-06 London: The Stationary Office Ltd. 25 July 2006.

II. Royal College of Ophthalmologists: Response to Health Select Committee's Inquiry into ISTCs. [http://www.rcophth.ac.uk/ docs/press/PressRelease25July2006.pdf].

12. Wallace WA: Comparable statistics required (letter). [http:// www.bmi.com/cgi/eletters/332/7549/614\#1301 17].

13. Department of Health: Hewitt announces full-scale clinical audit of ISTCs. In Press release 2006/0 I57 London: Department of Health.

14. Commission for Healthcare Audit and Inspection: Independent sector treatment centres. A review of the quality of care. Healthcare Commission 2007.

15. Deprivation [http://www.statistics.gov.uk/StatBase/Prod uct.asp? vlnk=942 I \&More $=$ Y] 
16. Bayliss EA, Ellis JL, Steiner JF: Subjective assessments of comorbidity correlate with quality of life health outcomes: Initial validation of a comorbidity assessment instrument. Health and Quality of Life Outcomes 2005, 3:5I-58.

17. Dolan P: Modelling valuations for EuroQol health states. Medical Care 1997, 35:1096-I 108.

18. Steinberg EP, Tielsch JM, Stein OD, et al.: The VFI 4: An index of functional impairment in patients with cataract. Arch Ophthalm 1994, I I 2:630-638.

19. Garratt AM, Macdonald LM, Ruta DA, Russell IT, Buckingham JK, Krukowski $\mathrm{ZH}$ : Towards measurement of outcome for patients with varicose veins. Quality in Health Care 1993, 2:5-10.

20. Dawson J, Fitzpatrick R, Carr A, Murray D: Questionnaire on the perceptions of patients about total hip replacement. J Bone Joint Surg $\mathrm{Br}$ 1996, 78: 185-90.

21. Dawson J, Fitzpatrick R, Carr A, Murray D: Questionnaire on the perceptions of patients about total knee replacement. J Bone Joint Surg $\mathrm{Br}$ 1998, 80:63-9.

22. Jenkinson C, Layte R, Lawrence K: Development and testing of the Medical Outcomes Study 36-item Short Form health survey summary scale scores in the United Kingdom: results from a large-scale survey and clinical trial. Med Care 1997, 35:410-6.

23. Black NA, Sanderson CFB: Day surgery - development of a questionnaire for eliciting patients' experiences. Quality in Health Care 1993, 2:157-I6I.

24. Stata Corporation: Statistical Software: Release 9. College Station, Texas 2007.

25. Bellan L: Why are patients with no visual symptoms on cataract waiting lists? Can J Ophthalmol 2005, 40:433-8.

\section{Pre-publication history}

The pre-publication history for this paper can be accessed here:

http://www.biomedcentral.com/1472-6963/8/78/prepub

Publish with Biomed Central and every scientist can read your work free of charge

"BioMed Central will be the most significant development for disseminating the results of biomedical research in our lifetime. "

Sir Paul Nurse, Cancer Research UK

Your research papers will be:

- available free of charge to the entire biomedical community

- peer reviewed and published immediately upon acceptance

- cited in PubMed and archived on PubMed Central

- yours - you keep the copyright 